\title{
Noonan's syndrome diagnosed at second decade of life
}

\begin{abstract}
In 1963 Noonan and Ehmke described an autosomal dominant condition called Noonan syndrome in a group of patients with abnormal facial deformations, congenital heart diseases and various malformations. Its Incidence is 1 in 1000 to 2500 live births. One can miss the diagnosis in mildly affected cases as it usually depends on clinical features. We are presenting a case of a $24 y$ r old Egyptian male, who was incidentally diagnosed to have Noonan's Syndrome by means of morphological, clinical and echocardiographic \& magnetic resonance imaging (MRI) findings. This young patient had frequent spells of loss of consciousness. ECG showed runs of ventricular tachycardia with evidence of biventricular hypertrophy and severely impaired LV systolic function by ECHO. Treatment and prognosis varies from individual to individual according to its severity. Our patient was referred to electrophysiology department and underwent ICD implantation for secondary prevention of sudden cardiac death. This case report gives a clear cut management pathway when dealing with a newly identified adult Noonan. Most of the cases need multidisciplinary approach.
\end{abstract}

Keywords: noonan's syndrome, asymmetrical hypertrophy, hypertrophic cardiomyopathy
Volume 3 Issue 5 - 2017

\author{
Mohammed Al Jarallah,' Rajesh Rajan,' \\ Raja Dashti,' Ahmad Mousa Doaa, ${ }^{2}$ Bassam \\ Bulbanat ${ }^{\prime}$ \\ 'Department of Cardiology, Al-Amiri Hospital, Kuwait \\ ${ }^{2}$ Specialist in Clinical Genetics, Kuwait
}

\section{Correspondence: Rajesh Rajan, Department of Cardiology, Sabah Al Ahmad Cardiac Center,Amiri Hospital, Kuwait,} Email cardiology08@gmail.com

Received: July 03, 2017 | Published: July 20, 2017
Abbreviations: MRI, magnetic resonance imaging; ICD, international classification of diseases; LOC, loss of consciousness; $\mathrm{EF}$, ejection fraction; RV, right ventricular; LV, left ventricular; IQ, intelligence quotient; GI, gastrointestinal

\section{Introduction}

Noonan syndrome is one of the commonest genetic disorders caused by RAS-MAPK signal pathway alteration characterized by various congenital malformations. ${ }^{1,2}$ The prevalence is estimated as 1 in every 1000 to 2500 live births. ${ }^{3}$ It usually presents with developmental delay, short stature, a broad and webbed neck, typical facial features, chest deformities, scoliosis, cryptorchidism, bleeding disorders, congenital heart disease, intellectual disability, neurological $\&$ lymphatic disorders. ${ }^{4}$

\section{Case report}

A 24year old Egyptian laborer, presented to our emergency room with complaints of loss of consciousness (LOC) lasting for about $1-2$ minutes during his work as a manual labor. He experienced several such occurrence of transient LOC during the past 30days prior to this episode. Last episode was preceded by palpitations for 1-2seconds. He is a known smoker with no history any drug abuse. He had history of cryptorchidism and underwent orchidopexy. No other past medical history. On general examination patient had facial dysmorphic features, webbed neck, high nasal bridge, short stature $(5.38 \mathrm{feet} / 164 \mathrm{~cm})$, pectus excavatum \& scoliosis (Figure 1) (Figure 2). His heart rate was 70 beats per minute, blood pressure $120 / 80 \mathrm{mmHg}$, respiratory rate 20 per minute, saturation $99 \%$ on room air. Jugular venous distention was noted with no evidence of pedal edema. Cardiomegaly was clinically evident and on auscultation wide split with loud S2 was noted. Chest air entry was bilaterally equal. Abdomen was soft and hepatomegaly was noted. Chest X-ray Figure 3 showed cardiac enlargement.
Electrocardiogram Figure 4 showed normal sinus rhythm with rate $70 / \mathrm{min}$, $\mathrm{P}$ wave $120 \mathrm{msec}$ and $3 \mathrm{~mm}$, notching of $\mathrm{P}$ wave in II, bifid $\mathrm{P}$ in V1, PR 180msec, QRS $80 \mathrm{msec}$, QR pattern in III\&V1, V1 R/S=35/9 , V5 R/S=25/10, S1 Q3 T3 pattern noted. Laboratory investigations showed: $\quad \mathrm{WBC}=5.210^{9} / \mathrm{L}, \quad \mathrm{Hb}=14 \mathrm{~g} / \mathrm{L}$, Platelet Count $=16110^{9} / \mathrm{L}$, $\mathrm{GLU}=4.5 \mathrm{mmol} / \mathrm{L}, \quad \mathrm{BUN}=10.4 \mathrm{mmol} / \mathrm{L}, \quad$ Creatinine $=80 \mathrm{umol} / \mathrm{L}$, $\mathrm{Na}+=136 \mathrm{mmol} / \mathrm{L}, \mathrm{K}+=4.52 \mathrm{mmol} / \mathrm{L}$, Trop-i $=0.08 \mathrm{ng} / \mathrm{mL}, \mathrm{CK}=470 \mathrm{ng} /$ $\mathrm{mL}, \mathrm{CKMB}=48 \mathrm{ng} / \mathrm{mL}$, Vit D Level $=9.51 \mathrm{nmol} / \mathrm{L}$. Twenty-four hour Holter monitoring done was within normal limits. Ultrasound abdomen showed right grade 1 nephropathy and hepatomegaly. Transthoracic echocardiography showed Impaired left ventricular (LV) systolic function ejection fraction (EF) around $30-35 \%$ with a picture of hypertrophic cardiomyopathy with bi ventricular hypertrophy and bi-atrial dilatation. Cardiac MRI showed moderate to severe LV systolic dysfunction with $\mathrm{EF}$ of $32 \%$, moderate right ventricular (RV) systolic dysfunction, bi-atrial enlargement, asymmetrical hypertrophic cardiomyopathy with left \& right ventricular (mild $\mathrm{RVH})$ involvement. Genetic screening done and was inconclusive as it require further analysis (Figure 5) (Figure 6).

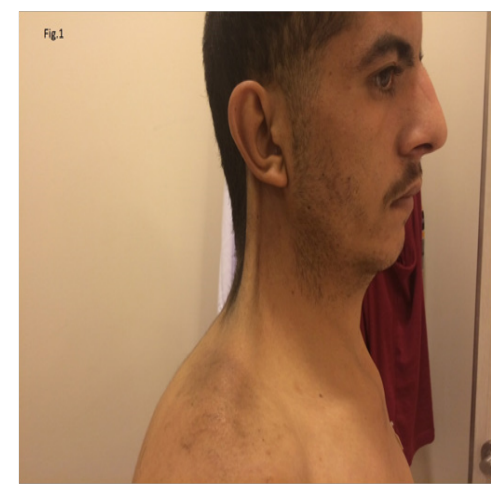

Figure I Pectus excavatum \& scoliosis. 


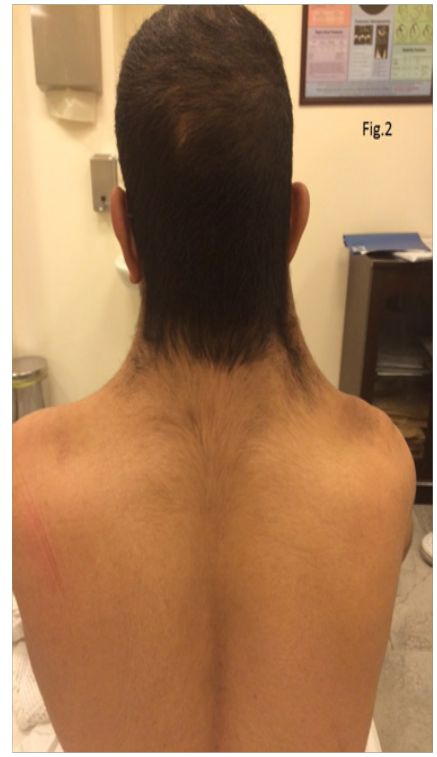

Figure 2 Pectus excavatum \& scoliosis.

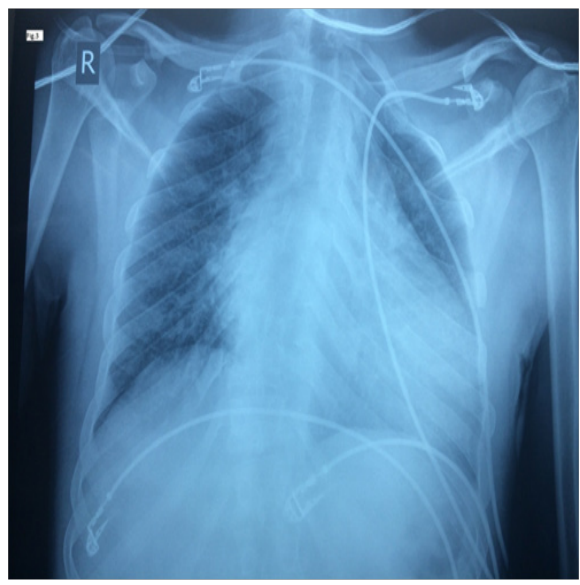

Figure 3 Chest X-ray.

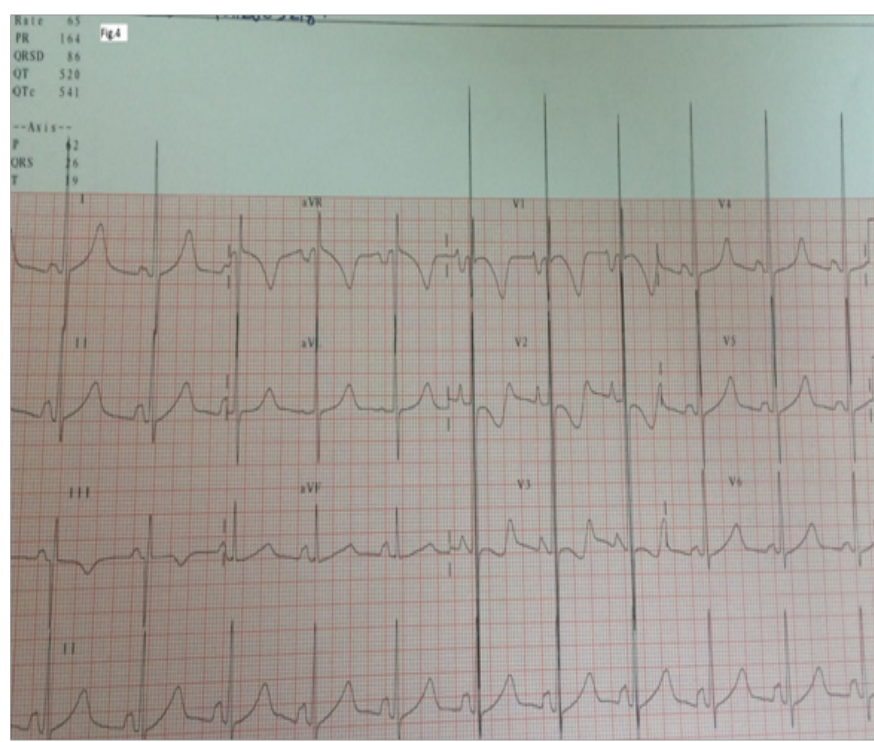

Figure 4 Electrocardiogram.

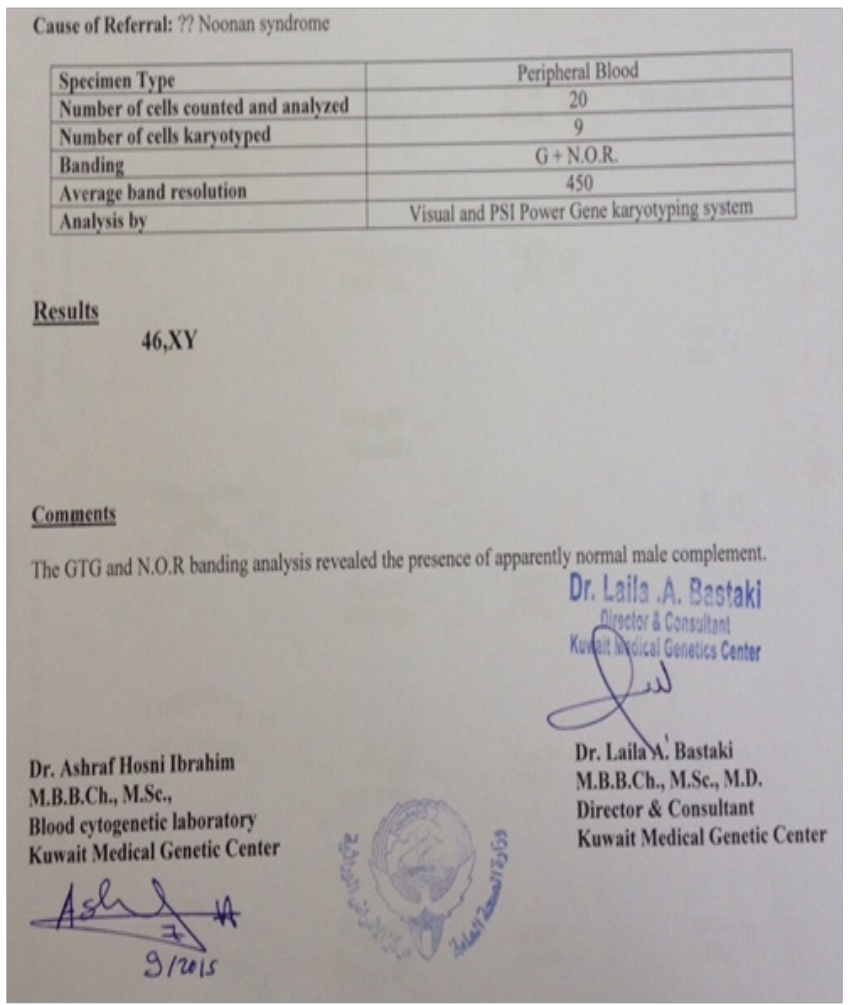

Figure 5 Cytogenetic laboratory report.

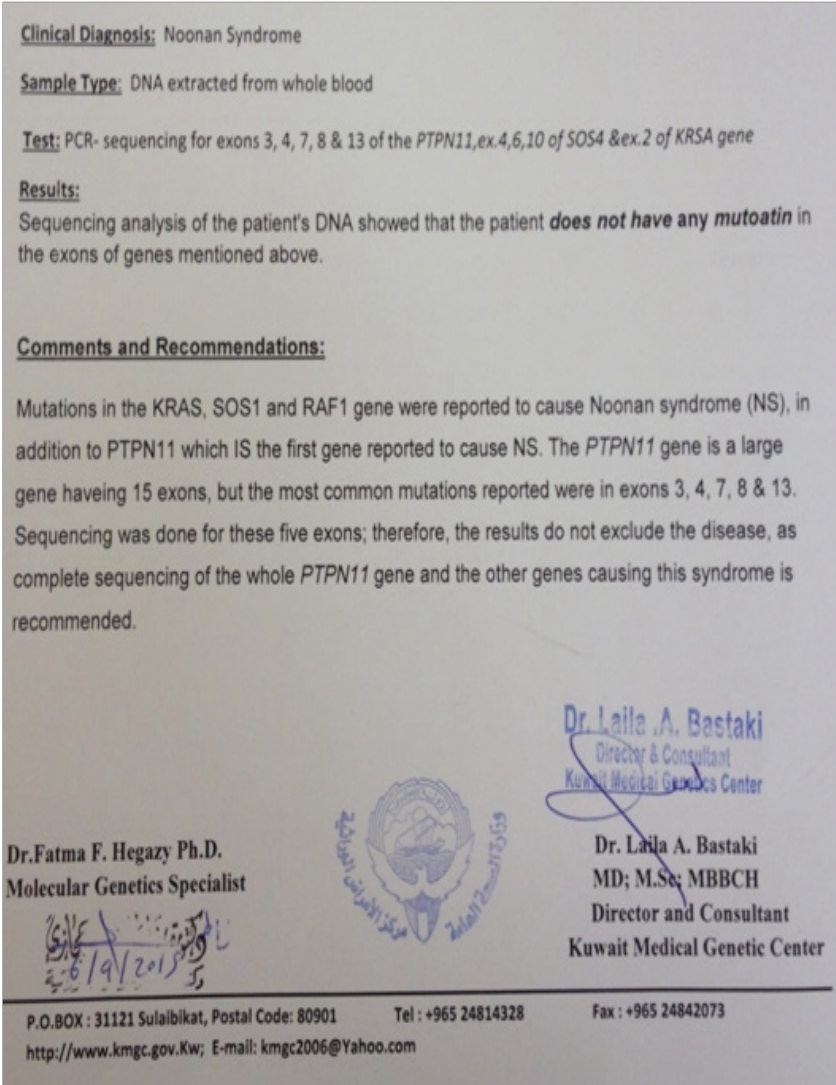

Figure 6 Molecular genetic laboratory report. 


\section{Discussion}

In Noonan Syndrome we can observe a multi system involvement in regard to clinical presentation. Literature review shows that Noonan is a pan-ethnic syndrome and the incidence is similar in both males and females. It is very difficult to diagnose Noonan at childhood since the facial dysmorphology features will be more evident as the child grows. Delayed puberty is one of the commonest features seen in male Noonan. We are reporting an adult male Noonan case which was left undiagnosed till the age of 24years.

Majority of the patients have normal intelligence. Mental retardation with low intelligence quotient (IQ) and memory are seen in almost $25 \%$ of Noonan patients. ${ }^{5}$ In our case, patient had no signs of mental retardation. Short stature and delayed growth are seen in 50$70 \%{ }^{6}$ Our patient had a short stature with height $(5.38 \mathrm{feet} / 164 \mathrm{~cm})$. Scoliosis and spinal deformities are common findings in Noonan and $30 \%$ of the cases its evident. ${ }^{7}$ Scoliosis was evident in our case and was confirmed by chest X-ray.

Manifestations on skin differ from case to case. It may be in the form of lentigines, Keratosis pilaris, café au lait spots, pigmented nevi. ${ }^{7}$ There was no evidence of any kind of skin manifestations in our patient.

Facial dysmorphic features are characteristic of Noonan. Refractive errors Amblyopia \& Strabismus are commonly seen in Noonan. Our patient had facial dysmorphic features but no refractory errors. Facial shape usually appears triangular. Head circumference will be nonproportionate to the face. Shape of the nose will be broad and short with high nasal bridge. Philtrum will be deeply grooved. Short neck with webbing is a classical feature. Low set ears, hypertelorism also seen in such patients. ${ }^{8,9}$ Our patient had a triangular face and short neck with webbing and large head.

Hearing defect of low and high frequency range can be seen $10 \%$ and $25 \%$ respectively. ${ }^{10}$ Dental malocclusion and microagnathia are seen in Noonan cases. ${ }^{4}$ Our patient had no hearing defect or dental malocclusion. Pectus excavatum and carniatum is also considered as a characteristic feature. ${ }^{3}$ Pectus excavatum was present in our case.

Cardiovascular manifestations/congenital heart diseases associated with Noonan syndrome are hypertrophic cardiomyopathy, pulmonary valve stenosis, atrial septal defect, ventricular septal defect, tetralogy of fallot and coarctation of aorta. ${ }^{11}$ Our patient had a cardiac MRI which revealed asymmetric LVH with normal left ventricular volume. Moderate to severe LV systolic dysfunction $\mathrm{EF}=32 \%$ and markedly elevated myocardial mass in diastole $231 \mathrm{~g}(147 \mathrm{~g} / \mathrm{m} 2)$. A faint patchy enhancement noted at the inferior insertion point and mid lateral wall. Normal right ventricular (RV) volume and moderate right ventricular dysfunction $\mathrm{EF}=31 \%$. Mild RV hypertrophy and hypertrabeculations noted. No SAM at rest. Biatrial enlargement noted. Features are suggestive of asymmetric hypertrophic cardiomyopathy with RV involvement (Figure 7).

Gastrointestinal (GI) abnormalities are seen mainly during childhood. Hepatosplenomegaly is seen in almost $25 \%$ of the patients. ${ }^{12}$ Our patient was free of any GI disorders. Delayed puberty and male gonadal dysfunction can be present in such cases. Cryptorchidism will be present around $80 \%$ of the Noonan patients. ${ }^{13}$ Our patient had unilateral cryptorchidism for which he underwent surgical correction. Juvenile myelomonocytic leukemia, myeloproliferative disease with coagulation defects and increased bleeding tendency are not uncommon. ${ }^{14}$ Our patient had no such manifestations.
Noonan Syndrome manifestations are mainly due to the mutation of genes in the RAS-MAPK signaling pathway alteration. Out of all PTPN11 is the commonest and 50\% patients with cognitive dysfunction have PTPN11 mutations, $13 \%$ patients with normal cognitive function have SOS1 mutations, $5-17 \%$ patients with delayed puberty and hypertrophic cardiomyopathy have RAFl mutations and other mutations like NRAS, CBL, BRAF, KRAS, SHOC2, and MAP2K1 are not common. ${ }^{15,16}$ For our patient we performed only basic genetic study in view of financial constraints. Hence it was in conclusive.

Diagnosis of Noonan can be made easily by using the diagnostic criteria by Van der Burgt et al. ${ }^{5}$ (Table 1) Turners syndrome will mimic as Noonan in girls. Our patient had typical Noonan facial features with high nasal bridge, webbed neck, short stature, pectus excavatum, cryptorchidism, hypertrophic cardiomyopathy, kyphoscoliosis, hepatomegaly, mild renal dysfunction, delayed puberty. In all diagnosed noonan cases genetic counseling is vital as the risk of transmission to offspring in the coming generation is high as $50 \% .{ }^{17}$ Multidisciplinary management strategy is required for Noonan syndrome treatment. Careful evaluation with clinical features and proper genetic study will help physicians to manage the cases properly. ${ }^{18}$ Our patient was referred to electrophysiology department and underwent ICD implantation for secondary prevention of sudden cardiac death.

Table I Diagnostic criteria by Van der Burgt ${ }^{5}$

\begin{tabular}{|c|c|c|}
\hline Features & $A=$ Major & B = Minor \\
\hline I. Facial & $\begin{array}{l}\text { Typical facial } \\
\text { dysmorphology }\end{array}$ & Suggestive facial dysmorphology \\
\hline 2. Cardiac & $\begin{array}{l}\text { Pulmonary } \\
\text { Valve Stenosis, } \\
\text { Hypertrophic } \\
\text { Cardiomyopathy } \\
\text { and or typical ECG } \\
\text { changes }\end{array}$ & Other defects \\
\hline 3. Height & $<3^{\text {rd }}$ percentile & $<10^{\text {th }}$ percentile \\
\hline 4. Chest wall & $\begin{array}{l}\text { Pectus carniatum/ } \\
\text { excavatum }\end{array}$ & Broad thorax \\
\hline $\begin{array}{l}\text { 5. Family } \\
\text { History }\end{array}$ & $\begin{array}{l}\text { First degree relative } \\
\text { with definite } \\
\text { Noonan syndrome }\end{array}$ & $\begin{array}{l}\text { First degree relative with } \\
\text { suggestive Noonan syndrome }\end{array}$ \\
\hline $\begin{array}{l}\text { 6. Other } \\
\text { Features }\end{array}$ & $\begin{array}{l}\text { All of the following: } \\
\text { intellectual disability, } \\
\text { cryptorchidism, and } \\
\text { lymphatic vessel } \\
\text { dysplasia }\end{array}$ & $\begin{array}{l}\text { One of the following: intellectual } \\
\text { disability, cryptorchidism, or } \\
\text { lymphatic vessel dysplasia }\end{array}$ \\
\hline
\end{tabular}

\section{Noonan syndrome (NS) can be diagnosed if :}

I. IATypical Facial dysmorphology+One major (Any one major feature from $2 \mathrm{~A}$ to $6 \mathrm{~A}$ ) $=\mathrm{NS}$.

2. IATypical Facial dysmorphology+Two minor (Any two minor feature from $2 \mathrm{~B}$ to $6 \mathrm{~B})=\mathrm{NS}$.

3. IB suggestive dysmorphology+Two major (Any two major feature from $2 \mathrm{~A}$ to $6 \mathrm{~A})=\mathrm{NS}$.

4. IB suggestive dysmorphology+Three minor (Any three minor feature from $2 \mathrm{~B}$ to $6 \mathrm{~B})=\mathrm{NS}$. 


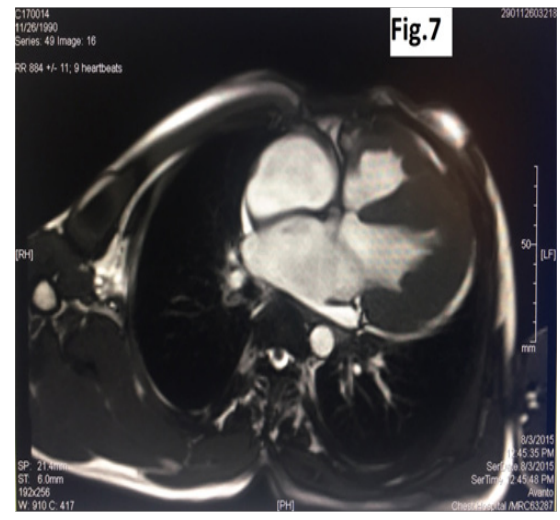

Figure 7 Asymmetric hypertrophic cardiomyopathy with RV involvement.

\section{Conclusion}

One should suspect Noonan Syndrome if the patient had typical facial dysmorphology, cardiac involvement, short stature, family history, delayed puberty, chest deformities and other features like low IQ and cryptorchidism. Type of associated congenital heart disease will influence the mortality and morbidity in Noonan. Multidisciplinary approach is mandatory as multiple systems were involved.

\section{Limitations}

In Kuwait genetic screening is not widely available and in most of the complicated cases samples are sent to UK and involve high cost. It's mostly done free for the citizens. For this patient we could manage to do few tests only. Our patient being an expat he was not financially sound enough to pay for further genetic screening.

\section{Acknowledgements}

None.

\section{Conflict of interest}

Author declares that there is no conflict of interest.

\section{References}

1. Pandit B, Sarkozy A, Pennacchio LA, et al. Gain-of-function RAF1 mutations cause Noonan and LEOPARD syndromes with hypertrophic cardiomyopathy. Nat Genet. 2007;39(8):1007-1012.

2. Marino B, Digilio MC, Toscano A, et al. Congenital heart diseases in children with Noonan syndrome: an expanded cardiac spectrum with high prevalence of atrioventricular canal. J Pediatr. 1999;135:703-706.
3. Mendez HM, Opitz JM. Noonan syndrome: a review. Am J Med Genet. 1985;21(3):493-506.

4. Romano AA, Allanson JE, Dahlgren J, et al. Noonan syndrome: clinical features, diagnosis, and management guidelines. Pediatrics. 2010;126(4):746-759.

5. Van Der Burgt I. Noonan syndrome. Orphanet J Rare Dis. 2007;2:4.

6. Sharland M, Burch M, McKenna WM, et al. A clinical study of Noonan syndrome. Arch Dis Child. 1992;67(2):178-183.

7. Lee CK, Chang BS, Hong YM, et al. Spinal deformities in Noonan syndrome: a clinical review of sixty cases. J Bone Joint Surg Am. 2001;83:1495-1502

8. Allanson JE. Noonan syndrome. J Med Genet. 1987;24(1):9-13.

9. Lee NB, Kelly L, Sharland M. Ocular manifestations of Noonan syndrome. Eye (Lond). 1992;6(pt 3):328-334.

10. Qiu WW, Yin SS, Stucker FJ. Audiologic manifestations of Noonan syndrome. Otolaryngol Head Neck Surg. 1998;118:319-323.

11. Raaijmakers R, Noordam C, Noonan JA, et al. Are ECG abnormalities in Noonan syndrome characteristic for the syndrome. Eur J Pediatr. 2008;167(12):1363-1367.

12. Shaw AC, Kalidas K, Crosby AH, et al. The natural history of Noonan syndrome: a long-term follow-up study. Arch Dis Child. 2007;92(2):128-132.

13. Marcus KA, Sweep CG, van der Burgt I, et al. Impaired Sertoli cell function in males diagnosed with Noonan syndrome. $J$ Pediatr Endocrinol Metab. 2008;21(11):1079-1084.

14. Kratz CP, Niemeyer CM, Castleberry RP, et al. The mutational spectrum of PTPN11 in juvenile myelomonocytic leukemia and Noonan syndrome/myeloproliferative disease. Blood. 2005;106(6):2183-2185.

15. Tartaglia M, Kalidas K, Shaw A, et al. PTPN11 mutations in Noonan syndrome: molecular spectrum, genotype-phenotype correlation, and phenotypic heterogeneity. Am J Hum Genet. 2002;70(6):1555-1563.

16. Maheshwari M, Belmont J, Fernbach S, et al. PTPN11 mutations in Noonan syndrome type I: detection of recurrent mutations in exons 3 and 13. Hum Mutat. 2002;20(4):298-304.

17. Allanson JE, Roberts AE. Noonan syndrome. Gene Tests: Reviews. National Center for Biotechnology Information. 2013.

18. Romano AA, Allanson JE, Dahlgren J, et al. Noonan syndrome: clinical features, diagnosis, and management guidelines. Pediatrics. 2010;126(4):746-759. 